\title{
Assessment of the impact of a parameter estimation method for the Nash Model on selected parameters of a catchment discharge hydrograph
}

\author{
Katarzyna Kołodziejczyk ${ }^{1, *}$ \\ ${ }^{1}$ Cracow University of Technology, Institute of Water Engineering and Water Management, \\ 24 Warszawska Str 31-155 Cracow, Poland
}

\begin{abstract}
An analysis of the usefulness of two parameter calculation methods ( $N$ and $k$ parameters) for the Nash Model was performed to transform effective rainfall into discharge based on two rainfall episodes gauged at the Kostrze gauging station as well as urban development data for the city of Cracow for 2014 and data obtained from a soil and agriculture map. The methods were the Rao et al. method and the Bajkiewicz-Grabowska method for regression relationships between instantaneous unit hydrograph model parameters and the physiographic parameters of a catchment. Effective rainfall was calculated for each rainfall episode using the SCS-CN method. A direct discharge hydrograph was calculated based on an effective rainfall hyetograph and using the Nash Model. Research has found that both studied methods yield comparable results, which indicates that both methods of effective rainfall transformation into discharge are useful. In addition, it has been shown that the impact of the Nash Model parameter estimation method on discharge hydrographs is minimal.
\end{abstract}

\section{Introduction}

Simple conceptual models find practical application in flood hydrograph modeling. Their main advantage consists in the small number of parameters, which makes them useful in ungauged catchments [1]. One of the frequently utilized models is the multi-reservoir instantaneous unit hydrograph (IUH) model created by Nash [2]. This model treats a catchment as a cascade of $N$ linear reservoirs connected in a sequence, where the first reservoirs is recharged by effective rainfall, and subsequent reservoirs are recharged with water by previous reservoir. The instantaneous unit hydrograph $[1,3,4,5]$ is obtained at the mouth of the last reservoir in this sequence of reservoirs. The Nash Model is a twoparameter model whose parameters are $k$ or storage parameter of each reservoir and $N$ - the number of reservoirs.

This paper provides an analysis of the usefulness of two methods for calculating the $N$ and $k$ parameters of the Nash Model: (1) Rao et al. method [6], (2) relationships

*Corresponding author: katarzyna.kolodziejczyk@iiiw.pk.edu.pl 
developed by Bajkiewicz-Grabowska [3] for the transformation of effective rainfall into discharge.

\section{Data}

The study area consists of the Potok Kostrzecki catchment. It is a right-bank tributary of the Vistula River within the city limits of Cracow. The catchment is located in the southwestern part of the city in District VIII (Dębniki) (Fig. 1). It is a catchment characterized by an "average" degree of urbanization (16.1\%), which is defined as the share of developed areas per total catchment surface area.

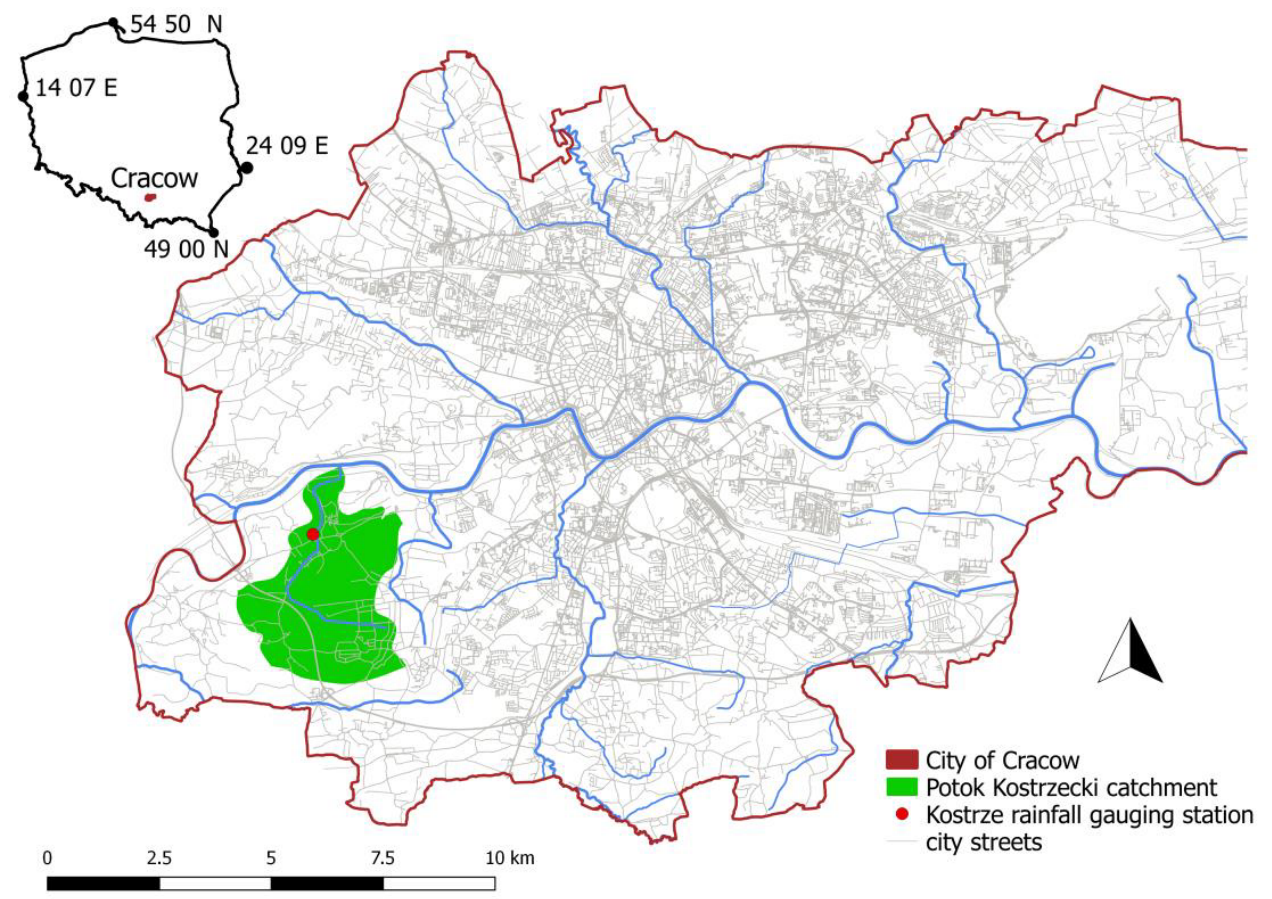

Fig. 1. Location of studied catchment.

Table 1 provides selected physiographic parameters for the studied catchment and stream.

Table 1. Selected catchment and stream parameters.

\begin{tabular}{|c|c|c|c|c|c|c|c|c|}
\hline $\begin{array}{c}A \\
\text { (cat. } \\
\text { surf. } \\
\text { area) }\end{array}$ & $\begin{array}{c}B \\
\text { (cat. } \\
\text { width) }\end{array}$ & $\begin{array}{l}H_{\max } \\
\text { (max. } \\
\text { elev.) }\end{array}$ & $\begin{array}{l}H_{\min } \\
\text { (min. } \\
\text { elev.) }\end{array}$ & $\begin{array}{c}\Delta H \\
\text { (height } \\
\text { diffs.) }\end{array}$ & $\begin{array}{c}J \\
\text { (cat. } \\
\text { grad.) }\end{array}$ & $\begin{array}{c}L \\
\text { (stm. } \\
\text { length) }\end{array}$ & $\begin{array}{c}i \\
\text { (stm. } \\
\text { grad.) }\end{array}$ & $\begin{array}{c}U \\
\text { (share } \\
\text { urban. } \\
\text { area) }\end{array}$ \\
\hline$\left[\mathrm{km}^{2}\right]$ & {$[\mathrm{km}]$} & [m a.s.1.] & [m a.s.l.] & {$[\mathrm{m}]$} & {$[\mathrm{m} / \mathrm{km}]$} & {$[\mathrm{km}]$} & {$[\% 0]$} & {$[\%]$} \\
\hline 10.32 & 1.66 & 260 & 200 & 60 & 9.68 & 5.96 & 6.3 & 16.11 \\
\hline
\end{tabular}

Rainfall data in the study area includes rainfall measured at the Kostrze gauging station over the period May 27, 2014 to November 28, 2014 and made available by Municipal Waterworks and Sewer Enterprise in Cracow Joint Stock Company (MPWiK S.A.). Two rainfall episodes characterized by the highest totals (Fig. 2) were selected for study purposes. Other data used in the study included data on land development in Cracow in 
2014 obtained from the Land Survey Department of the City of Cracow as well as soil data from a soil and agriculture map made available for study by the Voivodeship Center for Geodetic and Cartographic Documentation in Cracow.
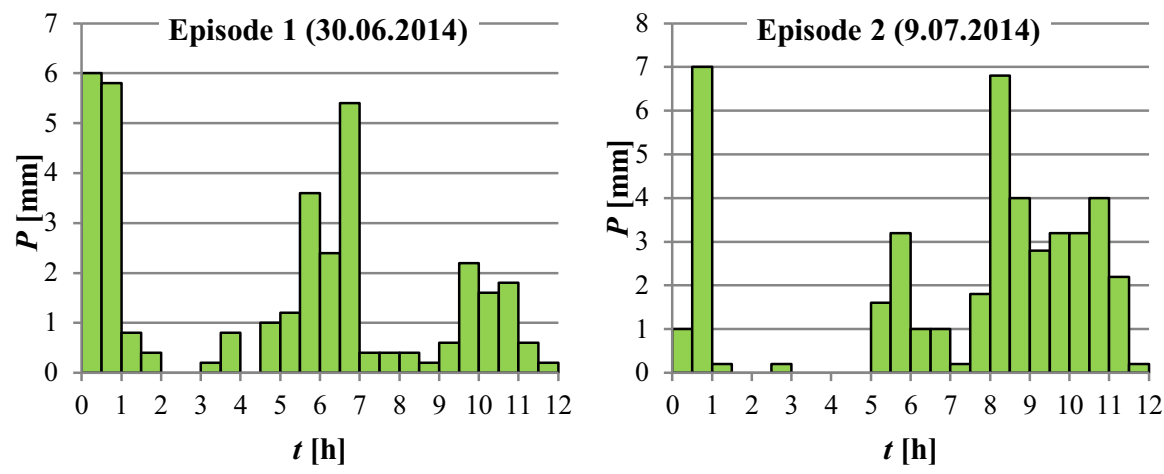

Fig. 2. Rainfall episodes.

\section{Methods}

The Nash Model treats the catchment as an imaginary retention reservoir recharged with effective rainfall $P_{e}$. The purpose of this type of model is to transform effective rainfall into discharge. Effective rainfall serves as the basic parameter in the Nash Model. In this study, this parameter was calculated for each rainfall episode using the SCS-CN method, which links effective rainfall with land use type, moisture levels in the catchment, soil type, and crop cultivation methods [7]. This method was created by the Soil Conservation Service of the United States, now known as the Natural Resources Conservation Service. It is used in the case of small and midsize catchments [8]. The SCS-CN method was adapted for use in Poland by Ignar [9] and other researchers. The details of this procedure are found in publication [10].

There exist a number of methods for estimating the $N$ and $k$ Nash Model parameters. The method proposed by Nash himself was that of moments, using initial moments of the first and second order of the gamma distribution. However, equations generated via this method turned out to be very sensitive to the quantity and accuracy of data, and also require accurate data on effective rainfall and discharge. Hence, this method cannot be used in many catchments. In order to make it possible to use the Nash Model for ungauged or inadequately gauged catchments, regression relationships were calculated between the $N$ and $k$ parameters and physiographic factors associated with each given catchment. Nash used data for a number of catchments in England to produce empirical formulas designed to determine his model's parameters [11].

Regression relationships between IUH model parameters and physiographic catchment parameters for Poland were generated by Bajkiewicz-Grabowska [3]. An attempt was also made to employ the geomorphologic instantaneous unit hydrograph (GIUH) to help estimate the $N$ and $k$ parameters for the Nash Model [12].

In this paper, two different estimation methods are used to determine the $N$ and $k$ Nash Model parameters: (1) Rao et al. method, (2) Bajkiewicz-Grabowska regression method. The parameters produced by each method were compared for resulting hydrographs. An analysis was then performed to assess the impact of each studied method of the estimation of the $N$ and $k$ parameters on the resulting discharge hydrograph.

According to the Rao et al. method [6], the runoff lag time $L A G$ decreases with total depth of effective rainfall, and increases proportionately to the length of effective 
precipitation time [13]. In this method, the value of the $k$ parameter is calculated using the following equation:

$$
k=0.56 \cdot A^{0.39} \cdot(1+U)^{-0.62} \cdot H^{-0.11} \cdot D^{0.22}
$$

where: $A$ - catchment surface area $\left[\mathrm{km}^{2}\right], U$ - share of developed land in catchment area [-], $H$ - depth of effective rainfall [mm], $D$ - effective rainfall duration [h].

The second parameter or the number of reservoirs $N$ is calculated as follows:

$$
N=\frac{L A G}{k}
$$

where $L A G$ or the discharge lag time equals $[5,13]$ :

$$
L A G=1.28 \cdot A^{0.46} \cdot(1+U)^{-1.66} \cdot H^{-0.27} \cdot D^{0.37}
$$

According to Bajkiewicz-Grabowska [3], the $N$ and $k$ parameters of the Nash Model are calculated based on physiographic parameters. The equation was formulated based on a study of 48 catchments in Poland and covers six physiographic parameters of the stream and catchment. These parameters were identified based on their relevance in the formation of surface runoff. The parameters represent four basic groups of catchment characteristics: (1) catchment geometry, (2) relief, (3) river network and drainage conditions, (4) land use $[3,4]$.

The overall relationship can be expressed as follows:

$$
N=\frac{5.66 \cdot T_{u}^{1.47} \cdot C_{z}^{3.62} \cdot J_{r}^{0.30}}{B_{m}^{1.02} \cdot D^{2.34}}
$$

where: $T_{u}$ - river network structure index $\left[\mathrm{km}^{-1}\right], C_{z}$ - catchment compactness index [-], $J_{r}$ - gradient of main stream $\left[\mathrm{m} \cdot \mathrm{km}^{-1}\right], B_{m}$ - maximum catchment width $[\mathrm{km}], D-$ mean river network density $\left[\mathrm{km} / \mathrm{km}^{2}\right]$;

$$
k=\frac{76.2 \cdot \lambda^{0.24}}{N^{0.81} \cdot J_{r}^{0.64} \cdot R_{L}^{0.92}}
$$

where: $\lambda$ - forest cover [\%], $R_{L}$ - stream length index.

The river network structure index $T_{u}$ is calculated using the following equation:

$$
T_{u}=\frac{\sum N_{i}}{O}
$$

where: $\sum N_{i}$ - number of streams (variable order) calculated on the basis of the river network classification by Strahler [-], $O$ - catchment circumference [km].

The catchment compactness index $C_{z}$ is defined as the relationship between the true circumference of the catchment $P$ and the circumference of a circle with a surface area equal to that of the catchment $(A)$ :

$$
C_{z}=0.28 \cdot \frac{P}{\sqrt{A}}
$$


The gradient of the main stream $J_{r}$ is calculated as follows:

$$
J_{r}=\frac{\Delta H}{L_{m}}
$$

where: $\Delta H$ - height difference [m], $L_{m}$ - maximum catchment length [km].

The mean river network density $D$ is an important parameter that serves to describe the degree of drainage possible in a given catchment. It is calculated as the quotient of the total length of all streams $L_{i}$ and the catchment surface area $A$ :

$$
D=\frac{\sum L_{i}}{A}
$$

Forest cover $\lambda$ is one of the most frequently used parameters characterizing land use. It is defined as the relationship between surface area covered by forests $A_{i}$ and total surface area $A$ of a given catchment:

$$
\lambda=\frac{A_{i}}{A}
$$

Stream length index $R_{L}$ :

$$
R_{L}=\frac{1}{M-1}\left(\frac{L_{2}}{L_{1}}+\frac{L_{3}}{L_{2}}+\cdots+\frac{L_{M}}{L_{M-1}}\right)
$$

where : $M$ - highest stream order in the catchment, $L_{i}$ - mean length of sections of order $i$.

Once the $N$ and $k$ parameters are calculated via the two selected methods, and the Nash Model is applied, a direct discharge hydrograph may be calculated as follows:

$$
Q_{i}=\sum_{j=1}^{i} h_{i-j+1} \cdot \Delta H_{j}, \quad i=1,2, \ldots,
$$

where: $h_{i}$ - unit hydrograph values $\left[\mathrm{m}^{3} \cdot \mathrm{s}^{-1} \cdot \mathrm{mm}^{-1}\right], \Delta H_{j}$ - depth of effective rainfall in the $j$-th time interval $[\mathrm{mm}]$.

\section{Effective rainfall}

The determination of effective rainfall is very important from the perspective of surface runoff analysis, as discharge hydrographs are calculated using this type of data, which constitutes that part of total precipitation that becomes transformed into surface runoff and eventually reaches the stream. Surface runoff begins at the point where precipitation exceeds the catchment's retention capacity $[9,11,14-17]$.In the SCS-CN method, effective rainfall equals total rainfall less losses due to interception, infiltration, surface retention, and surface evaporation [9]. The $C N$ parameter covers all factors affecting effective rainfall: soil type, land use, moisture conditions, other factors.

In this study, the $C N$ parameter needed to be adjusted due to moisture conditions in the studied catchment (antecedent precipitation totals) in the case of both rainfall episodes. All rainfall episodes occurred in the vegetation season, where antecedent precipitation totals for the second (average) level of catchment moisture must remain within the 35 to $53 \mathrm{~mm}$ interval. Lower or higher values require a first or third moisture level designation and an appropriate adjustment of the $C N$ parameter (Tab. 2) [15]. 
Table 2. Adjustment of the $C N$ parameter to reflect catchment moisture levels.

\begin{tabular}{|l|c|c|}
\hline Rainfall episode & 1 & 2 \\
\hline Soil moisture level & II & II \\
\hline Antecedent precipitation total [mm] & 19.6 & 0.4 \\
\hline Adjusted level of soil moisture & I & I \\
\hline$C N[-]$ parameter & 69 & 69 \\
\hline Adjusted $C N[-]$ parameter & 49.5 & 49.5 \\
\hline
\end{tabular}

In the case of episode no. 1, effective rainfall appeared after 5.5 hours from the start of rainfall (Fig. 3). The effective rainfall total equaled $1 \mathrm{~mm}$. The studied catchment is an area with a large share of forests, meadows, and agricultural land, which substantially increases its initial ability to retain rainwater. In addition, the data used in this study were collected at a time when the catchment was dry (low moisture level), which also caused a large part of the precipitation to infiltrate into the dry soil. As a result, effective rainfall was lower and also appeared later than normally.
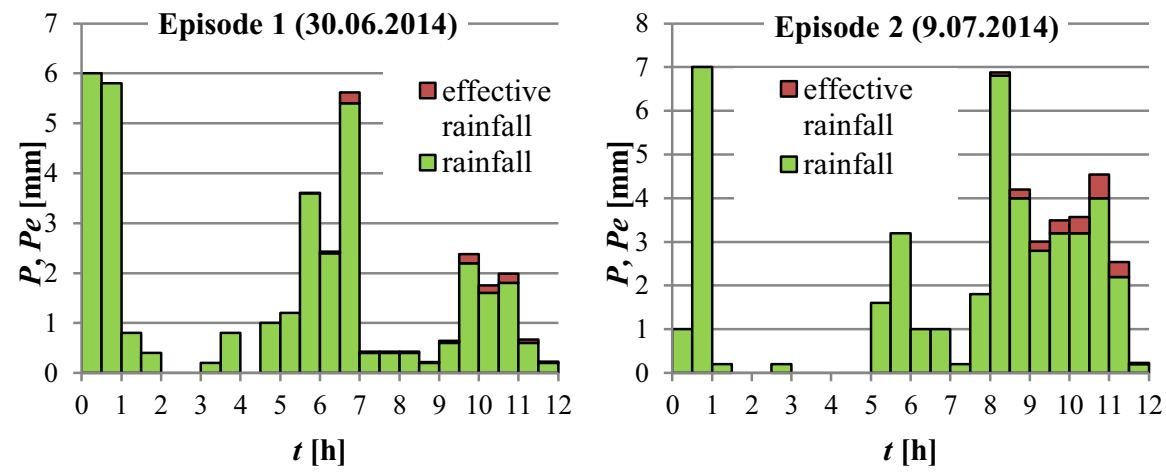

Fig. 3. Effective rainfall $P_{e}$.

Episode no. 2 occurred nine days after episode no. 1. The occurrence of episode no. 1 did not produce a significant impact on catchment moisture levels (also low moisture levels). The start of effective rainfall occurred eight hours after the start of rainfall, and its total equaled $2.06 \mathrm{~mm}$ (Fig. 3).

\section{$5 \mathbf{N}$ and $\boldsymbol{k}$ parameters in the Nash Model}

The following discharge hydrograph parameters were used to compare hydrographs that were produced based on model parameters calculated both using the Rao et al. method and the Bajkiewicz-Grabowska method: (1) time needed to reach a peak $T_{p},(2)$ height of peak wave $q_{p}$.

Figures 4 and 5 illustrate that the time needed to reach peak wave $T_{p l}$ calculated using the Rao et al. method and the time needed to reach $T_{p 2}$ calculated via the BajkiewiczGrabowska method are equal for episodes no. 1 and no. 2 . The value for episode no. 1 is 12 $\mathrm{h}$, and $12.5 \mathrm{~h}$ for episode no. 2 . 


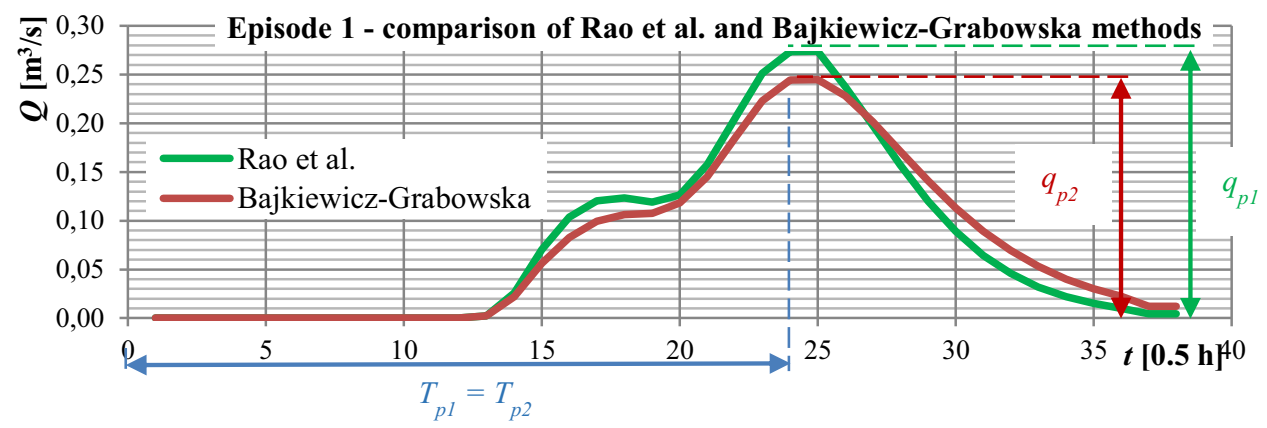

Fig. 4. Discharge hydrographs for episode no. 1.

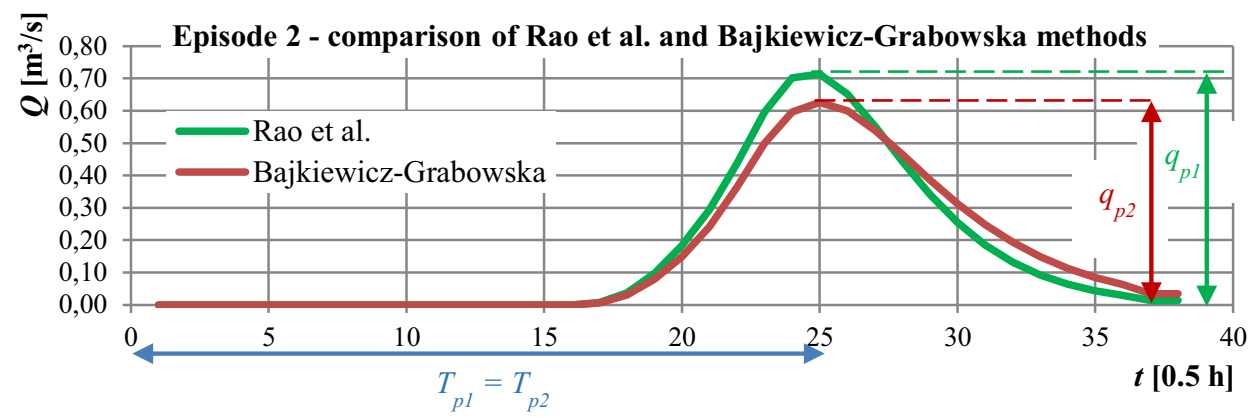

Fig. 5. Discharge hydrographs for episode no. 2.

The wave peak $q_{p l}$ calculated using the Rao et al. method is slightly higher in both cases than the wave peak $q_{p 2}$ calculated for parameters estimated using the BajkiewiczGrabowska equation. For episode no. 1, the wave peak for the Rao et al. method equals $0.27 \mathrm{~m}^{3} / \mathrm{s}$, while for the Bajkiewicz-Grabowska method, it is $0.24 \mathrm{~m}^{3} / \mathrm{s}$. For episode no. 2, the corresponding values are as follows: $0.71 \mathrm{~m}^{3} / \mathrm{s}, 0.63 \mathrm{~m}^{3} / \mathrm{s}$. The shape of the hydrograph for each examined episode is similar.

\section{Summary and conclusions}

The impact of the estimation method for parameters $N$ and $k$ in the Nash Model on several discharge hydrograph parameters was assessed using real rainfall data from 2014 along with land use data and soil type data for the study area. It has been shown that both compared discharge hydrograph parameters are either equal or close to equal, which further implies that the impact of estimation methods for the $N$ and $k$ parameters in the Nash Model is small. The Rao et al. method and the Bajkiewicz-Grabowska equation yield comparable results, which means that both methods can be used to transform effective rainfall into discharge.

The Rao et al. method requires little information about the catchment, which allows it to be used for hydrograph construction when complete observation data are unavailable [18]. It is successfully applied by many authors, among others Jovanovic [19], Banasik et al. [20]. Research has demonstrated that the hydrograph computed using Rao et al. method is approximate to the hydrograph calculated on the basis of rainfall-runoff data [18]. 
This study was part of a larger research endeavor: „Modern methods of design and management in engineering and water management", task 2: Application of the DPSIR analysis for assessment of state and prediction of flow dynamics and river-bed changes for the Vistula River and its tributaries in the Cracow agglomeration area.

\section{References}

1. A. Byczkowski, Hydrologia (Hydrology) (SGGW, II, 1999)

2. J. E. Nash, IASH - General Assembly of Toronto, T. III. (1958)

3. E. Bajkiewicz-Grabowska, Przegląd Geofizyczny, Zeszyt 4, Rocznik XXX (1985)

4. U. Soczyńska (red.), Hydrologia dynamiczna (Dynamic hydrology) (PWN, 1997)

5. K. Banasik, Wyznaczanie wezbrań powodziowych $w$ matych zlewniach zurbanizowanych (Assessment of flood events in small urban catchments) (SGGW, 2009)

6. R. A. Rao, J. W. Delleur, B. S. P. Sarma, J HYDR ENG DIV-ASCE, ASCE Vol. 98 (HY7) (1972)

7. K. S. Mishra, V. P. Singh, Soil Conservation Service Curve Number (SCS-CN) Methodology (Water Science and Technology Library, Vol. 42, 2003)

8. D. H. Pilgrim, I. Cordery, Flood runoff, in: D. R. Maidment (ed.), (McGraw-Hill, Inc. Handbook of hydrology, 1993)

9. S. Ignar, Metodyka obliczania przeplywów wezbraniowych $w$ zlewniach nieobserwowanych (Calculation methods for flood discharge in ungauged catchments) (SGGW, 1993)

10. K. Kołodziejczyk, Acta Scientiarum Polonorum, seria Formatio Circumiectus, 15, $4(2016)$

11. J. E. Nash, Applied flood hydrology, in: R. B. Thorn (ed.), (River engineering and water conservation works, Butterworths, 1966)

12. Z. Ziemońska, J. Żelaziński, Przegląd Geofizyczny, T. XXLX, z. 3. (1984)

13. A. Krajewski, K. Banasik, Acta Scientiarum Polonorum - Architectura, 12, 4 (2013)

14. V. Mockus, Soil Conservation Service (SCS) National Engineering Handbook, Section 4. Hydrology, (Soil Conservation Service, US Department of Agriculture, Washington, D.C., 1964)

15. M. Ozga-Zielińska, J. Brzeziński, Hydrologia stosowana (Applied hydrology) (Wydawnictwo naukowe PWN, 1994)

16. J. Pociask-Karteczka, Zlewnia. Właściwości i procesy (The catchment-properties and processes) (Wyd. Uniwersytetu Jagiellońskiego, 2006)

17. E. Bajkiewicz-Grabowska, Z. Mikulski, Przegląd Geofizyczny, T. XXLX, z. 3. (1984)

18. A. Sikorska, K. Banasik, Acta Scientiarum Polonorum - Architectura, 7, 4 (2008)

19. J. Jovanovic, Hydrologic approches In Urban drainage system modeling, Proceedings of the 3rd International Conference "Urban Storm Drainage", C. Maksimiwic, M. Radojkovic (eds.), Pergamon Press, Oxford, UK 185-208 (1986)

20. K. Banasik, M. Barszcz, L. Hejduk, Current and perspective flood flow consequences of land use changes in Sluzew Creek (suburb of Warsaw), Special aspects of urban flood management, Proceedings Coast Session Aquaterra Conference 2007, Technische Universitat Hamburg, 3-16 (2007) 